\title{
Quantification of the distribution of cetylpyridinium chloride on the external and internal surfaces of montmorillonite: Relevance in antifungal activity assessment
}

\author{
Florencia Yarza ${ }^{\mathrm{a}}$, Cesar Fernández Morantes ${ }^{\mathrm{a}}$, María L. Montes ${ }^{\mathrm{b}}$, Natalia Bellotti ${ }^{\mathrm{c}}$, \\ Joaquin Salduondo ${ }^{a}$, Saadet Yapar ${ }^{\mathrm{d}}$, Fernanda Cravero ${ }^{\text {a }}$, Rosa M. Torres Sánchez ${ }^{\text {a, }}$ \\ ${ }^{\text {a }}$ CETMIC, CONICET, CIC-CCT- La Plata, Camino Centenario y 506, CP 1897, M.B. Gonnet, Argentina \\ b IFLP, Instituto de Física La Plata, CONICET CCT-La Plata, Dep. de Física, Facultad de Cs. Exactas, UNLP, La Plata, Argentina

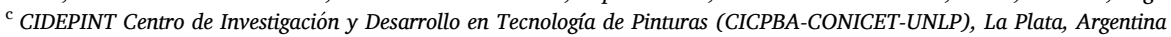 \\ ${ }^{\mathrm{d}}$ Ege Univ. Eng. Fac., Chemical Engineering Dep, 35100, Bornova-İmir, Turkey
}

\section{H I G H L I G H T S}

- Montmorillonites with cetylpyridinium (CP) adsorbed were evaluated against 2 fungi.

- The CP adsorption on montmorillonites occurred by three different interactions.

- DTGA allowed quantifying the \% of adsorbed CP in the processes involved.

- The inhibition diameters for both fungi were related to their susceptibility to CP.

- Materials with antifungal activity for technological applications.

\section{A R T I C L E I N F O}

\section{Keywords:}

Montmorillonite

Cetylpyridinium chloride

Interaction processes

Antifungal activity

\begin{abstract}
A B S T R A C T
Two raw bentonites, from Argentina (Mt-A) and Turkey (Mt-T), rich in montmorillonite, were loaded with different concentrations of cetylpyridinium chloride (CP), ranging from $50 \%$ to $150 \%$ of their respective cation exchange capacity (CEC). Their antifungal activity was tested against Alternaria alternata and Chaetomium globosum. Thermal analysis was used to identify the different surface adsorption sites of the CP on the montmorillonite (Mt) samples as well as to quantify the surfactant amount related to each process, which could play a key role in the antifungal capacity of the synthesized materials. Three different $\mathrm{CP}$ interaction processes with the Mt surface sites were observed. Two occurring at the outer Mt surface (electrostatic interaction between $\mathrm{CP}$ and the negative surface sites of Mt (B), and van der Waals (VdW) interactions between long tails of CP molecules (A) and one at the inner (or interlayer) Mt surface due to the cation exchange between $\mathrm{CP}$ and the inorganic interlayer cations (C). The simultaneous occurrence of these processes was confirmed by the increase of the interlayer thickness due to the entrance of $\mathrm{CP}$ by $\mathrm{C}$ process and the decrease of the initial negative zeta potential values by $\mathrm{A}$ and $\mathrm{C}$ processes, respectively.

The antifungal activity of clays against strains of $A$. alternata and $C$. globosum, was evaluated by agar diffusion assay. Then, the inhibition diameter was related to the actual $\mathrm{CP}$ load and its distribution according to $\mathrm{A}, \mathrm{B}$, and $\mathrm{C}$ processes. Samples with the highest inhibition zone, Mt-A-CP150, and Mt-T-CP150, presented the greatest actual CP loaded (103 and 110\% CEC, respectively). For both samples, the CP amount related to the A process was the lowest, with values around $10 \% \mathrm{CEC}$, while the major contribution occurs for the $\mathrm{CP}$ related to the B process (49.9 and 57.7\% CEC, respectively). The Pearson correlation coefficients $\rho$ determined between inhibition zone diameters and $\mathrm{CP}$ amount related to each adsorption process indicated that the $\mathrm{A}$ and $\mathrm{B}$ processes play a key role in the controlled release of the $\mathrm{CP}$ from the organoclays.

For A. alternata the $\rho$ values for A and B processes resulted in 0.84 and 0.87 , while for C. globosum 0.84 and 0.91 , respectively, being non-significant for $\mathrm{C}$ process in both cases.
\end{abstract}

\footnotetext{
* Corresponding author.

E-mail addresses: rosa.torres@gmail.com, rosats@cetmic.unlo.edu.ar (R.M. Torres Sánchez).
} 
These results allow proposing these materials for possible antifungal applications, preventing CP degradation, and enhancing the durability of the materials.

\section{Introduction}

Exposure to mold may result in human illness through three different mechanisms: infection, allergy, and toxicity [1]. Particularly, indoor environments, especially kitchens and bathrooms, cannot usually maintain a constant humidity and temperature during the day, prompting the growth of fungal species [2]. In this sense, species of the genera Alternaria, Cladosporium, Phoma, and Aureobasidium can easily attain growth from the hyphal tip within minutes [3].

The proven antibacterial and antifungal capacity of different quaternary ammonium compounds (QAC) [4] has led to their wide distribution in hospitals, industry, and cosmetics products. Particularly, cetylpyridinium, CP, is a QAC-based surfactant that exhibits germicidal properties and it is used in medicine, cosmetics, food, and detergents industry, among others. The antibacterial properties of CP against Gram-positive bacteria, Staphylococcus aureus, and Bacillus subtilis, as well as Gram-negative bacteria, Pseudomonas aeruginosa, Escherichia coli, and Proteus vulgaris, were reported [5,6].

In order to improve the biocidal activity of materials and their lifespan, current research focuses on materials with simultaneous biocidal action: contact killing and released based biocidal action $[7,8]$. In this sense, the biocide could be supported by a solid matrix to encapsulate the molecules, improving product quality by delaying its degradation and providing a controlled biocide release [9].

One of the most common clays that presently recognized adsorption and/or encapsulation capacity of quaternary amines is montmorillonite (Mt). Worldwide Mt samples modified by the incorporation of CP have been proposed as antimicrobial materials, achieving different effectiveness [10]. It was found that a CP loading of $50 \%$ of the cation exchange capacity (CEC) of Mt maintained its antibacterial properties against $S$. aureus [12]. However, antibacterial capacity, indicated as percentage reduction of plate counts, against Salmonella enteritidis range within 39 and $99 \%$ when three Mt of different origins were exchanged with $150 \%$ of the respective CEC [13]. Recently, it was proposed that surface interactions with the hydrophobic tails of surfactant molecules cause the adhesion of bacteria on organo-Mt surfaces generating damage to cell membranes and causing their protein dysfunction [14]. Although important research has been done to demonstrate the effectiveness of CP on Mt against bacteria [12,15] there is not still research evaluating these composites against indoor fungi, as A. alternata and $C$ globosum.

The distribution of CP on Mt could be a key factor in the achieved antifungal activity of materials. Sorption of cationic surfactants onto phyllosilicates, as Mt clays, occurs into the Mt interlayer space, via cation exchange capacity and by the incorporation of $\mathrm{CP}$ into the Mt external surface [16-18]. Therefore, the quantification of CP located at the external surface of Mt could be a good indicative parameter to predict the antifungal activity of Mt-CP composites.

Several efforts have been performed to determine the distribution of the QAC cations on clays surface [19]. proposed a mathematical equation to quantify the amount of surfactant exchanged in clays under anoxic conditions. This calculation quantifies almost well the amount of incorporated organic, but it does not consider the formed products due to the pyrolysis of organic matter.

In this frame, this work presents the characterization of two (Turkey and Argentina) raw and CP loaded bentonites. The raw materials were loaded with different $\mathrm{CP}$ concentrations and evaluated as antifungal materials again against A. alternata (KU936229) or C. globosum (KU936228). The mathematical deconvolution of specific peaks of differential thermogravimetric analyses (DTGA) was proposed to calculate the actual loaded $\mathrm{CP}$ and also to evidence and quantify the interaction processes between $\mathrm{CP}$ and the different surfaces of the Mt, considered as a potentially crucial factor for the antifungal effect of the modified materials. For that, modifications to the mathematical model proposed by Ref. [19] were performed, considering sample humidity, complete organic matter oxidation, and clay dehydroxylation. Then, X-ray diffraction (XRD) analysis and zeta potential determinations were performed on all samples to identify the occurrence of the different interactions at the internal and external Mt surfaces, respectively.

\section{Materials and methods}

\subsection{Materials}

The Argentine bentonite labeled as Mt-A, rich in montmorillonite (Table 1), was used as received while the Turkish bentonite was purified according to the method used in a previous study [12] and labeled as Mt-T. The $<2 \mu \mathrm{m}$ fraction of the Mt-A sample, obtained by centrifugation at $15,000 \mathrm{rpm}$, to eliminate the coarse fraction impurities, was labeled as $\mathrm{Mt}-\mathrm{A} 2 \mu \mathrm{m}$ and used only to determine the structural formula of the Mt-A.

The Turkish bentonite (Mt-T) comes from the Resadiye-Tokat region, which is located in the province of Tokat in central-northeastern Anatolia, Turkey [20] (Fig. S1). It belongs to the Kapakli formation of Upper Cretaceous age (72-65 million years), [21]. These sediments were deposited in a shallow marine environment [21] giving rise to the bentonite levels formed by in situ alterations of the volcanic glass by hydrothermal and diagenetic processes [22] where seawater had a considerable effect.

Del Lago bentonite (Mt-A), as it is commercially known, comes from the Northwest of the province of Río Negro, Argentina (Fig. S1). This rock belongs to the Allen formation of the Malargüe Group, Upper Cretaceous in age [23]. The depositional environment corresponds to shallow waters of low energy, with a limited supply of fresh water in the presence of saline or slightly saline water [24,25], where the bentonite is composed of smectite clays formed after the alteration of volcanic glass coming from short pyroclastic events.

The CP chloride monohydrate $(\geq 96 \%)$, MW $=358.01 \mathrm{~g} \mathrm{~mol}^{-1}$, and critical micelle concentration (CMC) $1.03 \mathrm{mM}$ [26], was purchased from Sigma Aldrich and used as supplied.

\subsection{CP loaded montmorillonite samples preparation}

The CP loaded Mt-A or Mt-T samples were prepared following a similar procedure reported previously to obtain organo-montmorillonite [12]. Briefly, CP in amounts equivalent to the predetermined percentage of cation exchange capacity (CEC) values of the respective Mt samples ( $50 \%, 75 \%, 100 \%$ or $150 \%$ CEC) were dissolved in $25 \mathrm{~mL}$ of distilled water, and $1 \mathrm{~g}$ of clay was sprinkled under magnetic stirring at $400 \mathrm{rpm}$ and the dispersion stirred further $3 \mathrm{~h}$ at room temperature. At the end of the stirring period, the solid and liquid phases were separated by centrifugation at $14,000 \mathrm{rpm}$ for $10 \mathrm{~min}$. The solids were washed three times with distilled water to remove chloride anions, testing in the supernatants with $\mathrm{AgNO}_{3} 0.1 \mathrm{M}$, until they were free of chloride anions. The solids were dried in an oven at $60{ }^{\circ} \mathrm{C}$, and then ground in a mortar, and denoted as Mt-A-CP50, Mt-T-CP75, etc.

\subsection{Petrography identification, mineralogical composition (Rietveld method), cation exchange capacity (CEC), Mössbauer analysis, and structural formula determination}

Petrography images were obtained from random grain mounts 
immersed in Canadian balsam, using an Olympus BX60 petrographic microscope, to identify impurities remaining in the Mt purified samples.

Diffraction data were collected from powder samples X-rayed within $3^{\circ}<2 \theta<70^{\circ}$, using Bruker AXS D2 Phase equipment, with operating conditions: $40 \mathrm{kV}$ and $35 \mathrm{~mA}, \mathrm{Cu} \mathrm{K}_{\alpha}$ radiation, Ni filter, a step width of $0.02^{\circ}$, and $1.0 \mathrm{~s} \mathrm{step}^{-1}$ counting time. The estimated standard deviations were derived from individual scale factors calculated by the Fullprof method, for the respective phases, excluding other error contributions. Mineral quantification was obtained by the [27] method applied to the diffraction patterns.

The CEC value was determined using the $\left(\left[\mathrm{Cu}(\mathrm{en})_{2}\right]^{2+}\right.$ complex [28]. Concisely, the copper complex was added to Mt dispersions (10 $\mathrm{mg}$ $\mathrm{mL}^{-1}$ ) and magnetically stirred (400 rpm) for $3 \mathrm{~h}$. The supernatant was isolated by centrifugation at $14,000 \mathrm{rpm}$ for $10 \mathrm{~min}$ and used to quantify the $\left[\mathrm{Cu}(\mathrm{en})_{2}\right]^{2+}$, in a UV-visible spectrophotometer (Hewlett Packard 8453 ) at $\lambda=548 \mathrm{~nm}$. The experiments were performed in triplicate and the average CEC values were reported (Table 1). Mössbauer spectroscopy, based on the recoil-free resonant absorption of gamma rays, allows studying Fe environments on solid samples, such as clays. Hyperfine parameters, extracted from Mössbauer spectrum fit, give information about Fe oxidation state as well as the relative spectral area of each identified environment. Besides, in specific cases, it allows iron oxides identification. Mössbauer spectra were collected at room temperature using a standard spectrometer in a transmission geometry (512 channels and $\mathrm{a}^{57} \mathrm{CoRh}$ radioactive source). The detector system was calibrated using an $\alpha$-Fe foil and all the isomers shifts were referred to this standard. Since measurements performed at $12 \mathrm{~mm} \mathrm{~s}^{-1}$ revealed the absence of magnetic signals, the velocity was set to $4 \mathrm{~mm} \mathrm{~s}^{-1}$.

In order to attain the accurate elemental compositions of both Mt samples, X-ray fluorescence (XRF) analysis (Bruker S8 Tiger with dispersive wavelength) was used. The purified Mt-T was analyzed without further treatment, while for Mt-A sample the $<2 \mu \mathrm{m}$ fraction (labeled as Mt-A2 $\mu \mathrm{m}$ ) was used. The structural formula of Mt-T and MtA2 $\mu \mathrm{m}$ samples was determined from the chemical composition (\%) following the procedure proposed elsewhere [29]. The total charges from the octahedral and tetrahedral sheets were calculated by adding the deficiency or excess caused by the isomorphic replacement in each of them, as indicated by the structural formula [29].

\subsection{Thermogravimetric analysis}

Thermogravimetric analysis (TGA) was performed using Rigaku 8121 equipment with alumina as reference material. $20 \mathrm{mg}$ of samples were placed in alumina crucibles and heated from 24 to $1000{ }^{\circ} \mathrm{C}$ at a scanning rate of $10^{\circ} \mathrm{C} \mathrm{min}{ }^{-1}$ in air atmosphere. The first-order derivative of TGA (DTGA) was calculated in all cases.

The actual amount of surfactant loaded $(X)$ was determined from mass loss values obtained by the respective TGA, in a temperature range from 150 to $1000{ }^{\circ} \mathrm{C}$ (eq. (1)). Based on previous work [19], additional considerations were made: i) the organic matter present in the Mt-CP samples were combusted completely to a high temperature due to the oxidizing atmosphere used. ii) the mass losses percentages were normalized concerning the humidity of each sample (dry basis). iii) dehydroxylation of Mt was a process that occurs in all Mt-CP samples, which is proportional to the inorganic residue at the end of the process $\left(1000{ }^{\circ} \mathrm{C}\right.$ ). The $f$ factor (eq. (2)) was defined, considering the previous issues, and used to correct the dehydroxylation process of the Mt in the
Mt-CP samples. The $f$ factor ranges from 0 to 1 , where the highest value indicates the highest Mt proportion in samples.

$X=\frac{1000 \times\left(S_{o t}-\left(M t_{r t} \times f\right)\right)}{\mathrm{CEC} \times \mathrm{MW}}$

$f=\frac{\left(100-S_{o t}\right)}{\left(100-M t_{r t}\right)}$

In eq. (2) $S_{o t}$ is the mass loss percentage corresponding to the CP exchanged in each Mt sample at the temperature range studied, and $M t_{r t}$ is the mass loss percentage in the Mt in the same temperature range, to consider the structural dehydroxylation process. The percentage of mass loss indicated by the step-like drop in the TGA curve corresponds to the integrated area under DTGA peaks. The peaks of CP decomposition (from $150{ }^{\circ} \mathrm{C}$ to $400{ }^{\circ} \mathrm{C}$ ) were mathematically deconvoluted by fitting the signal to two or three Gaussian functions with $\mathrm{R}^{2} \geq 0.98$.

\subsection{X-ray diffraction and zeta potential analyses}

To assess the crystallinity changes between samples without and with different $\mathrm{CP}$ loading, X-ray diffraction patterns were recorded from 3 to $70^{\circ}(2 \theta)$ with the same equipment and conditions indicated previously for Rietveld analysis. Differences were evaluated by changes in 001 reflections. To determine the probable $\mathrm{CP}$ entrance to the Mt interlayer, the scheme and molecular size length were determined using geometry optimization tools (Jmol v. 14.80.20).

Electrokinetic potentials were determined using Brookhaven 90Plus/ Bi-MAS employing the electrophoretic mobility function. The electrophoretic mobility was converted into zeta potential values automatically using the Smoluchowski equation. The operating conditions were: $\lambda=$ $635 \mathrm{~nm}, 15-\mathrm{mW}$ solid-state laser, scattering angle of $90^{\circ}$ and temperature of $25{ }^{\circ} \mathrm{C}$. For each determination, $40 \mathrm{mg}$ of sample was dispersed in $40 \mathrm{~mL}$ of a $10^{-3} \mathrm{M} \mathrm{KCl}$ solution, used as an inert electrolyte, and the slurry was stirred. The $\mathrm{pH}$ dispersion was adjusted by dropwise addition of $\mathrm{HCl}$ or $\mathrm{KOH}$ at different concentrations and followed by magnetic stirring until equilibrium was established (10 $\mathrm{min})$.

\subsection{Antifungal assays}

The antifungal potential of the modified clay samples was assessed by agar well diffusion method by Ref. [30] with two fungal strains: A. alternata (KU936229) and C. globosum (KU936228) previously isolated from bio-deteriorated coatings and identified [31,32]. Petri dishes with $15 \mathrm{~mL}$ of Malt Extract Agar (MEA) medium inoculated with $200 \mu \mathrm{L}$ of the corresponding spore dispersions were prepared. The inoculum concentration was adjusted to $10^{5}$ spores $\mathrm{mL}^{-1}$ by the use of a Neubauer counting chamber. $7.0 \mathrm{~mm}$ diameter wells were punched out from the agar plate and each one was filled with $20 \mathrm{mg}$ of the tested material. The assay was done in triplicate with the corresponding controls (raw Mt-A and Mt-T samples). All the plates were incubated at $28^{\circ} \mathrm{C}$, and after $48 \mathrm{~h}$ inhibition zone diameters (ID) were measured. Solids with ID $\geq 7 \mathrm{~mm}$ were considered active against the strain tested and when the ID $<7 \mathrm{~mm}$ (fungal growth on material) were considered without antifungal activity.

Table 1

Cation exchange capacity (CEC), mineralogical composition as percentage wt. (Mt: Montmorillonite; Q: Quartz; F: Feldspar, Cris: Cristobalite, Cal: Calcite and Gyp: Gypsum) of indicated samples.

\begin{tabular}{llllllll}
\hline Sample & CEC $(\mathbf{c m o l}(+) / \mathbf{k g})$ & Mt $(\%)$ & Q (\%) & F (\%) & Cris (\%) & Cal (\%) & Gyp (\%) \\
\hline Mt-A & $87.3 \pm 0.8$ & $88.2 \pm 0.9$ & $5.2 \pm 0.4$ & $5.0 \pm 0.6$ & - & - \\
Mt-A2 $\mu \mathrm{m}$ & $97.5 \pm 0.9$ & 100.0 & - & - & - & - \\
Mt-T & $96.9 \pm 0.3$ & $96.0 \pm 0.8$ & - & - & $3.0 \pm 0.7$ & $1.0 \pm 0.4$ \\
\hline
\end{tabular}




\section{Results and discussion}

\subsection{Mt characterization}

To identify the presence of non-crystalline species and/or low amounts of crystalline species, not revealed by XRD analysis, several petrographic images were examined. Fig. 1 shows the petrography of random grain mounts for the Mt-A2 $\mu \mathrm{m}$ sample, where some gypsum crystals were identified with the clay aggregates, while for the Mt-T sample glass shards and calcite crystals together with the clay aggregates were detected. The presence of glass shards indicates that the sample still contains vitreous material that has not been completely transformed into bentonite and reaffirms, that the precursor was volcanic ash.

As a consequence of the interaction with marine waters (a natural sodium source), the bentonites formed were in both cases Na-bentonite type, corroborated by the oxide content determined by XRF (Table 2).

Figs. S3 (A) and (B) show the XRD patterns for Mt-A and Mt-T, together with the Rietveld analysis.

Particularly, the Mt \% increases for Mt-A2 $\mu \mathrm{m}$ respect to the Mt-A sample (Table 1 ) revealed the complete elimination of coarse material (within the detection limit of XRD, around 2\%). The presence of $\mathrm{SiO}_{2}$ as quartz and cristobalite species was detected in Mt-A and Mt-T samples respectively, while feldspar was found in Mt-A and calcite in Mt-T samples only.

The higher CEC value obtained for Mt-T (Table 1) than Mt-A was related mainly to the higher montmorillonite content in Mt-T [33], as also observed by the higher CEC value obtained for the purified Mt-A2 $\mu \mathrm{m}$ than for Mt-A sample.

The oxides content was within the range of those reported in the literature for this type of material [29]. The percentage of exchange ions $\mathrm{Na}^{+}, \mathrm{Ca}^{2+}$, and $\mathrm{K}^{+}$indicated a predominance of sodium montmorillonite in both samples, as it was expected by their genesis process.

The presence of iron in the crystalline structures of clay minerals significantly affects their physical and chemical properties [34], consequently, before determining the structural formula, the iron oxidation state present in the Mt structure must be detected to conclude whether it participates as $\mathrm{Fe}^{2+}$ or $\mathrm{Fe}^{3+}$. Mössbauer spectroscopy is the best technique to study Fe environments, so it was used to determine the iron oxidation state in both Mt samples. The Mössbauer spectrum of the Mt-T sample was fitted for the three characteristic Fe environments corresponding to montmorillonite clay [35] and a paramagnetic phase attributed to the relatively low Fe content (Table 3 and Fig. S3). Besides, around $3 \%$ of $\mathrm{Fe}^{2+}$ was found. For the Mt-A2 $\mu \mathrm{m}$ sample, the same $\mathrm{Fe}$ environments as those obtained for the Mt-T sample were identified, except for the presence of the $\mathrm{Fe}^{2+}$ phase [36].

The main oxides (Table 2) were used to obtain the structural formulae of both samples. Besides, to achieve more exact structural formulae, the presence of phases other than montmorillonite (Rietveld analysis and petrographic observations) was considered using the following corrections:

- In the Mt-T sample: the presence of $\mathrm{Fe}^{2+}$ phase (Mössbauer spectroscopy Table 3), was considered belonging to the octahedral sheet. The $\mathrm{SiO}_{2}$ value was modified by subtracting the $\mathrm{SiO}_{2}$ percentage amount corresponding to the cristobalite content (Table 1), and the $\mathrm{CaO}$ content was corrected by subtracting the percentage of calcite (Table 1).

- In the Mt-A2 $\mu$ m sample: the amount of $\mathrm{CaO}$ balanced with $\mathrm{SO}_{3}$ (Table 2) was assigned to gypsum $\left(\mathrm{SO}_{4} \mathrm{Ca} 2 . \mathrm{H}_{2} \mathrm{O}\right)$, evidenced in Fig. 1, and subtracted from the final $\mathrm{CaO}$ value.

The following structural formulae were obtained for each sample.

Mt-A2 $\mu$ m: $\mathrm{Si}_{3.81} \mathrm{Al}_{0.19}\left(\mathrm{Al}_{1.40} \mathrm{Fe}^{3+}{ }_{0.27} \mathrm{Mg}_{0.32}\right) \mathrm{O}_{10}(\mathrm{OH})_{2}\left(\mathrm{Na}_{0.37}\right.$ $\mathrm{Ca}_{0.06} \mathrm{~K}_{0.02}$ )

Mt-T: $\mathrm{Si}_{3.75} \mathrm{Al}_{0.25}\left(\mathrm{Al}_{1.47} \mathrm{Fe}^{3+}{ }_{0.24} \mathrm{Fe}^{2+}{ }_{0.02} \mathrm{Mg}_{0.24}\right) \mathrm{O}_{10}(\mathrm{OH})_{2}\left(\mathrm{Na}_{0.60}\right.$ $\mathrm{K}_{0.03}$ ).

\subsection{Thermogravimetric, $X R D$, and zeta potential analyses}

Peaks associated with the dehydration process of adsorbed water were found at $99.5{ }^{\circ} \mathrm{C}$ and $77.1^{\circ} \mathrm{C}$ for Mt-A and Mt-T samples, respectively (Fig. S4). Particularly, for the Mt-A sample, a second peak related to the dehydration process was found at $108.7^{\circ} \mathrm{C}$, linked with the higher $\mathrm{Ca}^{2+}$ content concerning the Mt-T sample (Table 2) [37]. In the same temperature range, important decreases in the intensity of the dehydration peaks (Fig. S4) and the mass loss \% value (Table 4) were found for the respective $\mathrm{CP}$ loaded Mt samples. This behavior evidenced the exchange of the raw hydrated interlayer cations by CP [38,39].

The dehydroxylation process of the octahedral structure observed at about $650-700{ }^{\circ} \mathrm{C}$ indicated the presence of the cis-vacant mineral in both raw Mt samples [40,41]. For CP loaded products this peak was also observed, although shifts towards lower temperatures, of around $600^{\circ} \mathrm{C}$, attributed previously to the penetration of the methyl groups of the surfactant into the siloxane layer [42]. Besides, the shoulder appearing at temperatures around $700{ }^{\circ} \mathrm{C}$ can be ascribed to the oxidation of charcoal and the formation of $\mathrm{CO}_{2}$ [43].

The peaks within $150-400^{\circ} \mathrm{C}$ (Fig. 2) were assigned to organic cation decomposition $[44,45]$. The DTGA peak fitting by using three Gaussian functions reveals the different adsorption interactions proposed by Ref. [17,18]; of CP onto Mt, defined here as A, B and C processes (Fig. 3). The $\mathrm{C}$ process, occurring at temperature $\geq 300{ }^{\circ} \mathrm{C}$, corresponds to $\mathrm{CP}$ at the interlayer Mt surface by cation exchange between $\mathrm{CP}$ and the inorganic interlayer cations. The B process, revealed at lower temperatures than C, occurs at the outer Mt surface by electrostatic interaction between $\mathrm{CP}$ and the negative Mt surface sites. Finally, the A process, observed at the lowest temperature $\leq 240{ }^{\circ} \mathrm{C}$ ( $\mathrm{CP}$ isolated decomposition

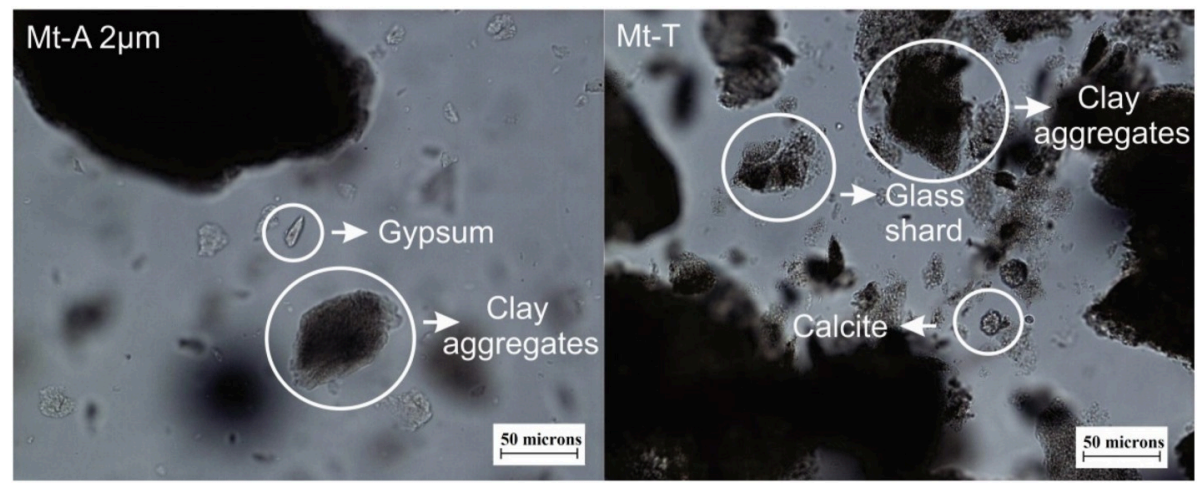

Fig. 1. Petrographic images of Mt-A2 $\mu \mathrm{m}$ and Mt-T samples with their mineral phases. 
Table 2

Oxides content (\%wt.) of indicated samples determined by XRF. Standard deviations were $<5 \%$.

\begin{tabular}{|c|c|c|c|c|c|c|c|c|c|c|c|}
\hline Sample & $\mathrm{SiO}_{2}$ & $\mathrm{Al}_{2} \mathrm{O}_{3}$ & $\mathrm{Fe}_{2} \mathrm{O}_{3}$ & $\mathrm{MgO}$ & $\mathrm{Na}_{2} \mathrm{O}$ & $\mathrm{CaO}$ & $\mathrm{K}_{2} \mathrm{O}$ & $\mathrm{TiO}_{2}$ & $\mathrm{BaO}$ & $\mathrm{MnO}$ & $\mathrm{SO}_{3}$ \\
\hline Mt-A2 $\mu \mathrm{m}$ & 62.29 & 22.00 & 5.92 & 3.55 & 3.12 & 1.25 & 0.26 & 0.54 & 0.03 & 0.04 & 0.39 \\
\hline Mt-T & 62.34 & 23.04 & 5.31 & 2.54 & 4.89 & 0.84 & 0.37 & 0.16 & - & 0.03 & 0.15 \\
\hline
\end{tabular}

Table 3

Mössbauer hyperfine parameters of Mt-A2 $\mu \mathrm{m}$ and Mt-T samples. $\delta$ and $\Delta$ represent the isomer shift and the quadrupole splitting in $\mathrm{mm} \mathrm{s}^{-1}$, respectively. RSA is the relative percentage of the spectral area.

\begin{tabular}{lll}
\hline \multirow{2}{*}{ Fe environment } & Sample & \\
\cline { 2 - 3 } & Mt-A2 $\mu \mathrm{m}$ & Mt-T \\
\hline $\mathrm{Fe}^{3+}(\mathrm{I})$ & $\delta=0.36$ & $\delta=0.34$ \\
& $\Delta=0.55$ & $\Delta=0.49$ \\
$\mathrm{Fe}$ & $\mathrm{RSA}=53 \pm 3$ & $\mathrm{RSA}=45 \pm 4$ \\
$\mathrm{Fe}^{3+}(\mathrm{II})$ & $\delta=0.37$ & $\delta=0.38$ \\
& $\Delta=1.15$ & $\Delta=1.38$ \\
$\mathrm{Fe}^{3+}(\mathrm{III})$ & $\mathrm{RSA}=22 \pm 2$ & $\mathrm{RSA}=23 \pm 2$ \\
& $\delta=0.095$ & $\delta=0.095$ \\
& $\Delta=0.01$ & $\Delta=0.01$ \\
$\mathrm{PR}^{3}$ & $\mathrm{RSA}=3 \pm 1$ & $\mathrm{RSA}=1 \pm 1$ \\
& $\delta=0.44$ & $\delta=0.39$ \\
$\mathrm{Fe}^{2+}$ & $\Delta=0.02$ & $\Delta=0.26$ \\
& $\mathrm{RSA}=22 \pm 2$ & $\mathrm{RSA}=28 \pm 3$ \\
& - & $\delta=1.15$ \\
& & $\Delta=2.88$ \\
& & $\mathrm{RSA}=3 \pm 1$ \\
\hline
\end{tabular}

value $237.9^{\circ} \mathrm{C}$, Fig. S5), related to the van der Waals (VdW) interactions between long tails of CP molecules interacting with Mt by B process.

Table 4 summarizes the total mass loss values for both raw Mt samples and their products loaded with $\mathrm{CP}$, indicated as actual surfactant loading (unit areas obtained were referred to as \% CEC of the respective raw Mt samples).

The DTGA analysis of peaks reveals that the external adsorption of $\mathrm{CP}$ occurs even in samples loaded with $\mathrm{CP}$ concentrations lower than $100 \%$ CEC, this allows concluding that adsorption of CP occurred simultaneously at the internal and external surface sites (see XRD and zeta potential sections), as also reported for HDTMA adsorption on Mt [46]. The increase of the CP concentration generates a higher concentration of $\mathrm{CP}$ molecules on the outer surface due to interactions between the alkyl chains by VdW forces. This causes a decrease in the degradation temperature of the $\mathrm{CP}$, approaching the temperature of the free $\mathrm{CP}$.

As shown in Table 4, generally the total actual CP loading percentages for Mt-A-CP samples were higher than those for Mt-T-CP samples being, the process $\mathrm{C}$ always higher for Mt-A, despite its lower CEC value, than for Mt-T samples (Table 1 ). Process $\mathrm{C}$ also increases with the initial
CP used concentrations, which can be also revealed by diffraction patterns analysis, due to it is directly connected to the d001 basal space. Fig. S6 A and B show the XRD patterns of Mt-A and Mt-T samples and their respective Mt-CP products.

The basal reflection of the Mt-A sample was fitted by two Voight functions $\left(\mathrm{R}^{2}=0.983\right.$; Fig. $\left.\mathrm{S} 6 \mathrm{~A}\right)$, which could be associated with the presence of hydrated $\mathrm{Na}^{+}$and $\mathrm{Ca}^{2+}$ ions at the interlayer $[37,39]$. However, for the Mt-T sample, the fit was to a single Voight function $\left(\mathrm{R}^{2}\right.$ $=0.999$ ) assigned to the hydrated $\mathrm{Na}^{+}$, which was the main cation present at the interlayer (Table 2). The amount of CP loaded and its arrangement in the interlayer of both Mt samples, shifted the basal reflection to lower $2 \theta$ values [47]. However, the different CEC values of montmorillonite samples, which are directly related to the total layer charge, could modify the surfactant bonding strength and its arrangement at the interlayer. Consequently, the $\mathrm{CP}$ arrangement at the Mt interlayer was until now related mainly to the total actual \% CP loaded (Table 4). The monolayer arrangement is observed for Mt-A-CP75 and Mt-T-CP75 samples because the interlayer thickness attained a value of $0.77 \mathrm{~nm}$ and did not permit the CP bilayer arrangement that needs at least $0.91 \mathrm{~nm}$ (Fig. S7).

When the CP actual loading increased up to around 80\% CEC for the Mt-A-CP100 sample (81.9\% CP actual loading, Table 4) the interlayer thickness value $(0.92 \mathrm{~nm})$ indicated that a CP bilayer arrangement was attained (Fig. S7) [47]. However, for the Mt-T-CP100 sample (77.7\% CP actual loading, Table 4), the peak of the basal reflection was enlarged and its deconvolution allowed determining two maxima at $1.77 \mathrm{~nm}$ and $1.85 \mathrm{~nm}$, which would indicate the presence of mono- and bilayer arrangements, respectively. For CP actual loading $\geq 100 \%$ CEC (Table 4), the interlayer thickness value was higher than $1.16 \mathrm{~nm}$ and consequently, the pseudo-trilayer arrangement prevailed in both samples [47].

$\mathrm{CP}$ percentages related to process A and B were higher in Mt-T-CP samples than in Mt-A one, these showed some preference of $\mathrm{CP}$ for external sites in Turkish samples (Fig. 3). Zeta potential measurements provide information about the modification of the electrical surface charge on the external surface by the increase in the loading amount of surfactants [48]. Fig. $4 \mathrm{~A}$ and B show zeta potential vs. pH curves for Mt-A and Mt-T samples and their corresponding CP-loaded samples, respectively.

For both raw montmorillonites, negative surface charge values were

Table 4

Mass loss percentage of the indicated Mt and CP loaded samples. The actual surfactant loaded (calculated with eq. (1)) was expressed as \% CEC, and the area of the DTGA peaks for each process was referred to as the actual CP loaded indicated as \% CEC. Associated errors were obtained performing error propagation of the corresponding equations [11]]. DRX basal reflection values are expressed in nanometers.

\begin{tabular}{|c|c|c|c|c|c|c|c|}
\hline \multirow[t]{2}{*}{ Sample } & \multicolumn{2}{|l|}{$\%$ mass loss } & \multirow[t]{2}{*}{ Total actual CP loading (\% CEC) } & \multirow[t]{2}{*}{ A process (\% CEC) } & \multirow[t]{2}{*}{ B process (\% CEC) } & \multirow[t]{2}{*}{$\mathrm{C}$ process (\% CEC) } & \multirow[t]{2}{*}{ d001 (nm) } \\
\hline & $25-150\left({ }^{\circ} \mathrm{C}\right)$ & $150-1000^{\mathrm{a}}\left({ }^{\circ} \mathrm{C}\right)$ & & & & & \\
\hline Mt-A & 11.7 & 5.5 & - & - & - & - & $1.26^{\mathrm{a}}$ \\
\hline Mt-A-CP50 & 3.0 & 18.1 & $47 \pm 1$ & - & $21.2 \pm 0.5$ & $25.8 \pm 0.4$ & 1.43 \\
\hline Mt-A-CP75 & 1.4 & 24.1 & $70 \pm 2$ & $2.2 \pm 0.5$ & $27.9 \pm 0.8$ & $39.3 \pm 0.7$ & 1.70 \\
\hline Mt-A-CP100 & 1.5 & 27.3 & $82 \pm 2$ & $7.4 \pm 0.6$ & $33 \pm 1$ & $41.6 \pm 0.5$ & 1.85 \\
\hline Mt-A-CP150 & 2.1 & 32.9 & $103 \pm 3$ & $10.6 \pm 0.3$ & $49.9 \pm 0.4$ & $42.5 \pm 0.6$ & 2.16 \\
\hline Mt-T & 8.5 & 5.4 & - & - & - & - & 1.24 \\
\hline Mt-T-CP50 & 1.7 & 17.8 & $41 \pm 1$ & - & $20.2 \pm 0.7$ & $20.8 \pm 0.8$ & 1.40 \\
\hline Mt-T-CP75 & 2.3 & 23.9 & $63 \pm 2$ & $1.1 \pm 0.4$ & $33.7 \pm 0.5$ & $28.2 \pm 0.7$ & 1.70 \\
\hline Mt-T-CP100 & 2.1 & 28.4 & $78 \pm 2$ & $9.7 \pm 0.8$ & $37.6 \pm 0.4$ & $30.7 \pm 0.6$ & $1.73^{\mathrm{a}}$ \\
\hline Mt-T-CP150 & 2.4 & 37.9 & $110 \pm 3$ & $10.0 \pm 0.3$ & $57.7 \pm 0.8$ & $42.3 \pm 0.5$ & 2.09 \\
\hline $\mathrm{CP}$ & 6.3 & 93.7 & 100 & - & - & - & \\
\hline
\end{tabular}

a The basal reflection of these samples was fitted by two Voight functions peaks (Fig. S6). 

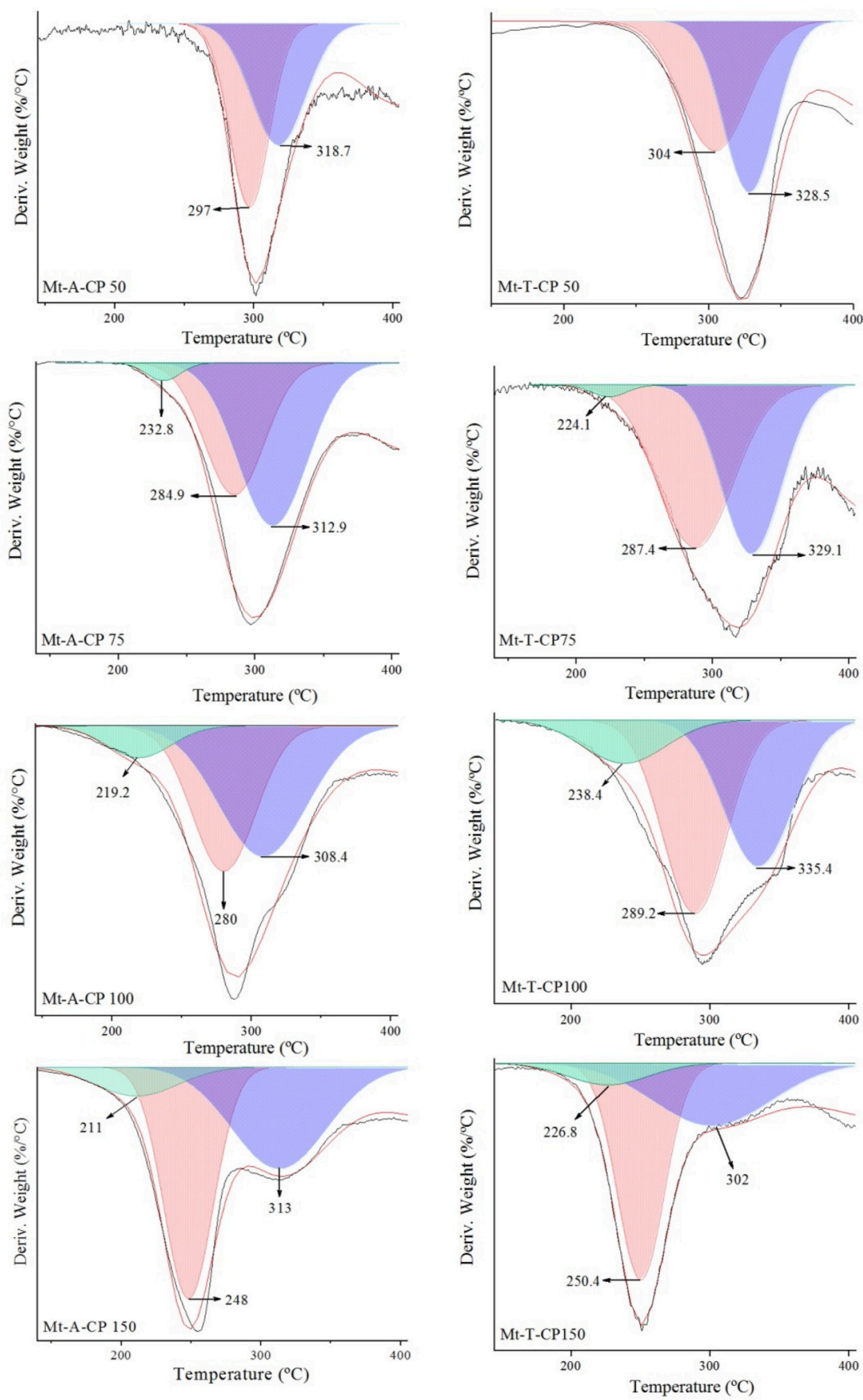

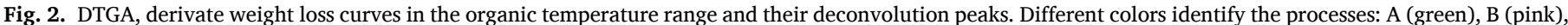

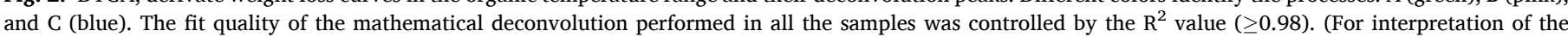
references to color in this figure legend, the reader is referred to the Web version of this article.)

found through the entire $\mathrm{pH}$ range evaluated, the zeta potential values resulted more negative for Mt-A than for Mt-T sample (around -35 and $-27 \mathrm{mV}$, respectively), in agreement with their respective lower CEC value (Table 1). This behavior is originated by the relative contribution of the Stern and diffuse layers to the permanent surface charge [49,50].

The CP loading increase generated a general shift towards less negative zeta potential values for all CP-loaded samples exchanged, concerning the corresponding raw Mt sample. The decrease in negative zeta potential values, even with the lower amount of CP loading, confirms the occurrence of processes A and B at the external Mt surface, which also supports the simultaneous existence of these adsorption mechanisms with that of process $C$ (revealed by XRD analysis). This decrease in the negative zeta potential values, with the increasing amount of $\mathrm{CP}$, was also assigned recently to a stronger effect of $\mathrm{pH}$ on the variable charges evidencing its participation, although the structural charges continue dominating the zeta potential behavior [51]. The CP concentration increase to actual loading $\geq 77 \%$ CEC reverses the zeta potential values to positive ones (Fig. 4), in agreement with the results found for other surfactants previously studied [52].

Particularly, for Mt-A-CP75 and Mt-T-CP75 samples, with an actual CP loading amount of 70\% CEC and 63\% CEC, respectively (Table 4), the $\mathrm{pH}$ dependence of the zeta potential sign allowed determining the isoelectric point of edge surface ( $\left(\mathrm{IEP}_{\text {edge }}\right)$ at around $\mathrm{pH}=3.5$. However, for Mt-T-CP100 sample (with actual CP loading $=78 \%$ ) the IEP $_{\text {edge }}$ shifted 

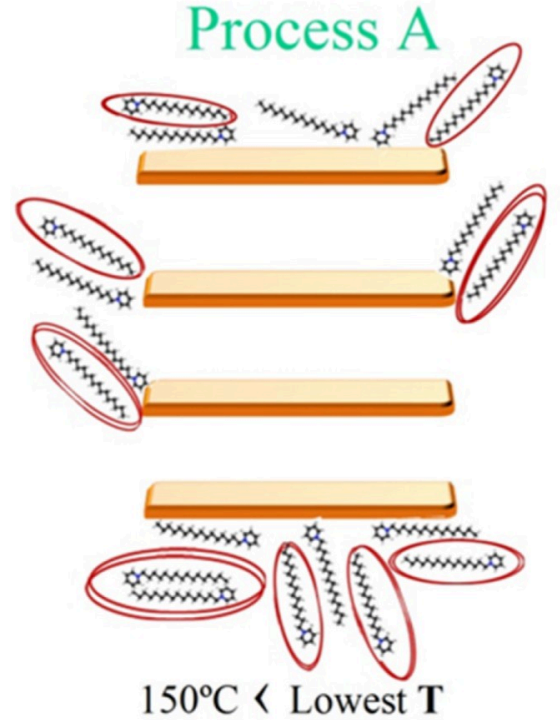

Van der Waals interactions.

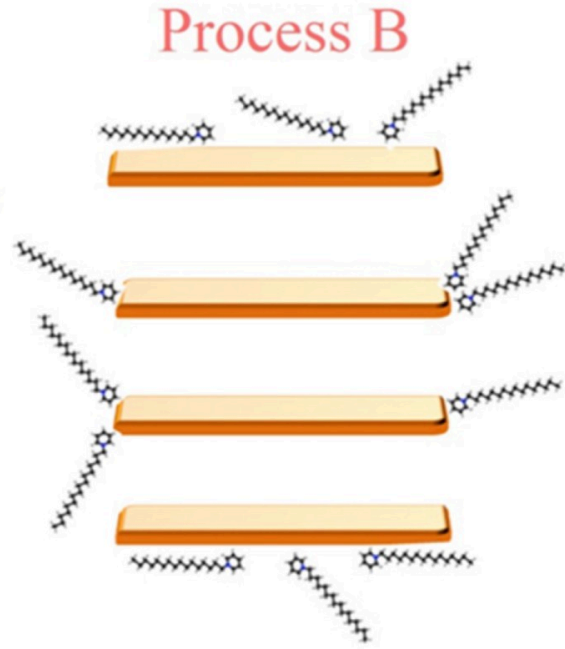

Intermediate $\mathbf{T}$

External electrostatic

\section{Process C}

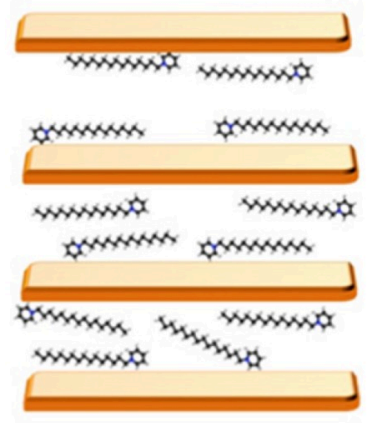

interactions.

\section{Highest $\mathbf{T}<400^{\circ} \mathrm{C}$}

Interlayer electrostatic interactions.

Fig. 3. Scheme of sorption processes (A, B and C) of CP on montmorillonite clays, proposed by the DTGA peaks from $150{ }^{\circ} \mathrm{C}$ to $400{ }^{\circ} \mathrm{C}$.
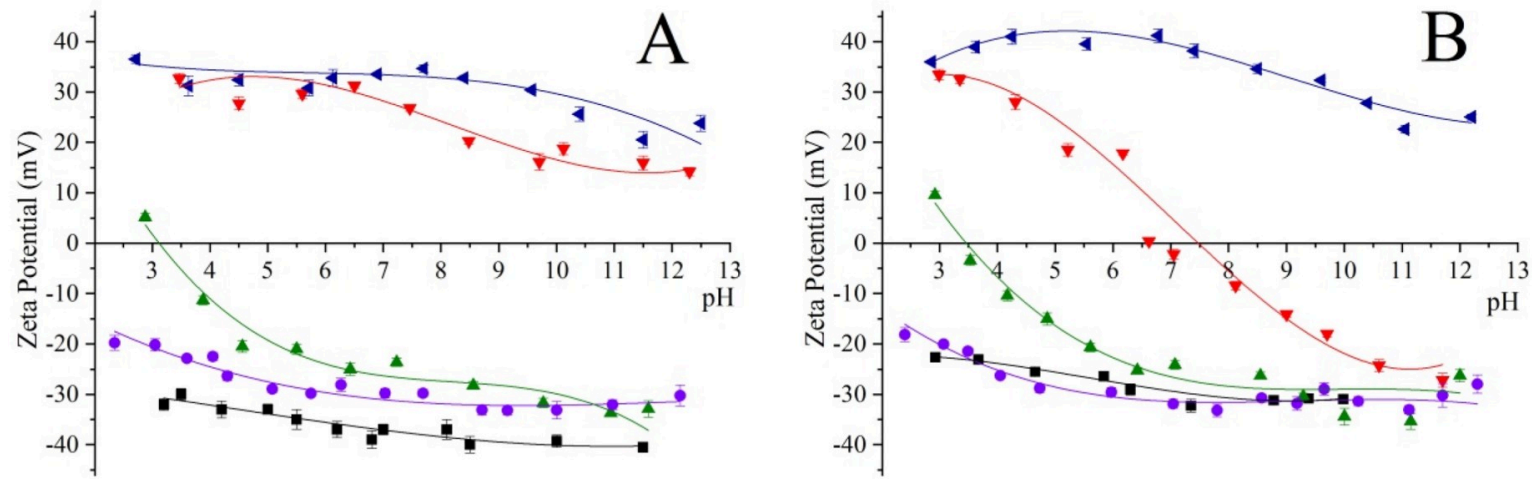

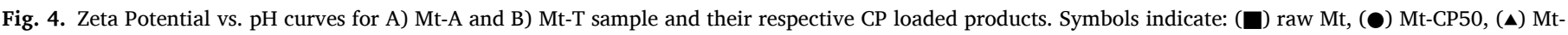
CP75 and ( $\nabla)$ Mt-CP100, ( $\triangleleft$ Mt-CP150 samples. Lines show the trends of the measured values.

to $\mathrm{pH}=7.5$. These shifts in the isoelectric point value are in agreement with results found by Refs. [51]; for different amounts of methylene blue loaded on a Mt with CEC $=0.96$ and assigned to the variable charge domination of the behavior. Finally, for samples with higher CP loaded a reversion to positive values can be observed, in line with the increasing percentage of processes $\mathrm{A}$ and $\mathrm{B}$. The $\mathrm{CP}$ concentration in all loaded Mt samples was almost 16-fold higher than the CMC of the CP and, thus, the surface adsorption of micelles should also be considered in these samples.

\subsection{Diffusion test results}

The images of the agar and the correspondent diameters of diffusion test against $C$. globosum and A. alternata are shown in Fig. 5 and Table 5. Both Mt samples with CP loading higher than 100\% CEC (actual $>77.8 \%$ CEC, Table 4) evidenced antifungal activity presenting inhibition zone higher than $7 \mathrm{~mm}$ except for Mt-A-CP100 sample where no growth was found on the surface (ID $=7$ ) against $C$. globosum.

Although CP has bacteriostatic activity by altering the permeability of cellular membranes [53], for CP loaded Mt samples the enhanced
Table 5

Diameters of diffusion -values in mm-test results expressed as mean \pm SD of the triplicates.

\begin{tabular}{lll}
\hline Sample & C. globosum & A. alternata \\
\hline Mt-A & $<7$ & $<7$ \\
Mt-A-CP50 & $7.0 \pm 0.1$ & $7.0 \pm 0.1$ \\
Mt-A-CP75 & $7.0 \pm 0.1$ & $7.0 \pm 0.1$ \\
Mt-A-CP100 & $7.0 \pm 0.1$ & $9.6 \pm 0.6$ \\
Mt-A-CP150 & $12.1 \pm 0.9$ & $18.9 \pm 0.5$ \\
Mt-T & $<7$ & $<7$ \\
Mt-T-CP50 & $7 \pm 0.1$ & $7.0 \pm 0.5$ \\
Mt-T-CP75 & $7 \pm 0.1$ & $7 \pm 0.3$ \\
Mt-T-CP100 & $9.6 \pm 0.7$ & $11.4 \pm 0.6$ \\
Mt-T-CP150 & $12 \pm 1$ & $13.9 \pm 0.9$ \\
CP & $40 \pm 2$ & $42 \pm 2$ \\
\hline
\end{tabular}

hydrophobicity and affinity of the CP loading at the clay surface are postulated as the antibacterial mechanism involved [13]. Furthermore, the lack of CP desorption of CP loaded Mt samples against Salmonella [13], and S. aureus and P. aeruginosa [12] indicated that, in these 


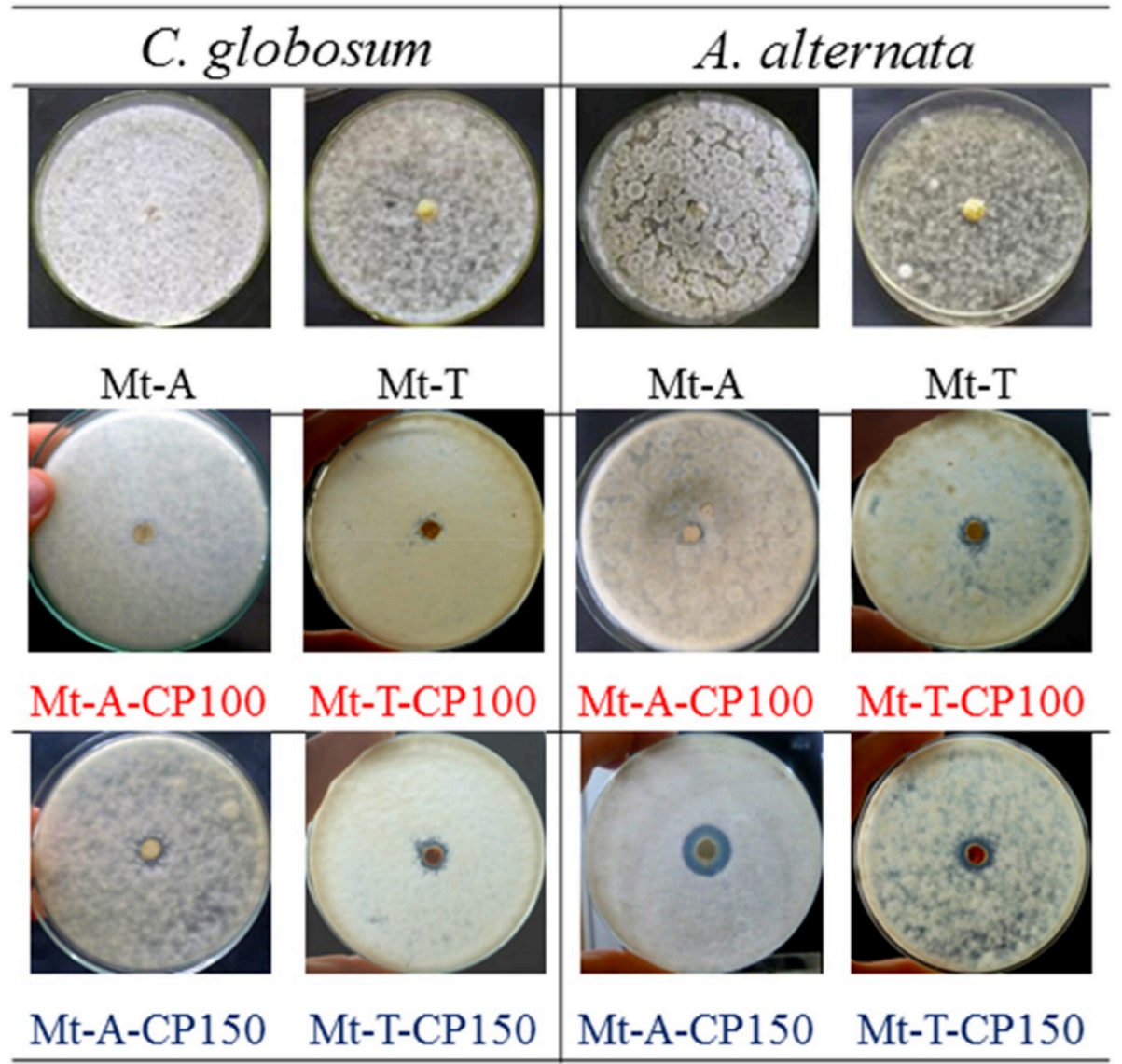

Fig. 5. Diffusion essay images against Alternaria alternata and Chaetomium globosum strains for Mt-A, Mt-T, Mt-A-CP100/150, and Mt-T-CP100/150 samples.

samples, the antibacterial effect is localized on the $\mathrm{CP}$ modified clay surface and is not due to $\mathrm{CP}$ dissociation from the clay. Recently, in previous work [54] authors reported a direct relation between the HDTMA addition to Mt and the antimicrobial activity, which indicated that HDTMA loaded at concentrations higher than the CEC leads to an increase in the membrane/OMMT interaction with the corresponding increase in antimicrobial activity (against $E$. coli and $S$. aureus).

Diffusion tests for isolated CP against both strains were tested (Fig. S8). The activity against both strains for raw Mt-A and Mt-T was null. Therefore, only the addition of $\mathrm{CP}$ is responsible for this bioactivity. The $\mathrm{CP}$ activity for some samples seemed to be limited to their surface (ID $=7 \mathrm{~mm}$ ), while clear inhibition zones diameters $\geq 7 \mathrm{~mm}$ for $\mathrm{Mt}$ samples with $\mathrm{CP}$ exchange corresponding to $100 \% \mathrm{CEC}$ and higher (81.9 and $77.8 \%$ actual total CEC, for Mt-A and Mt-T samples, respectively) were observed in the diffusion test (Fig. 4).

The inhibition zone, for both A. alternata and C. globosum, increases with the $\mathrm{CP}$ actual loading on both Mt samples (Fig. 6), exposing the antifungal activity of the CP, even though it is supported onto Mt samples. For the same amount of total $\mathrm{CP}$ loaded, the inhibition zone resulted higher for A. alternata than for $C$. globosum, for both Mt samples, indicating greater effectiveness of the $\mathrm{CP}$ against $A$. alternata than C. globosum.

Going deeper to understand if the CP distribution on the external or the internal surfaces of the Mt samples modifies the inhibition zone
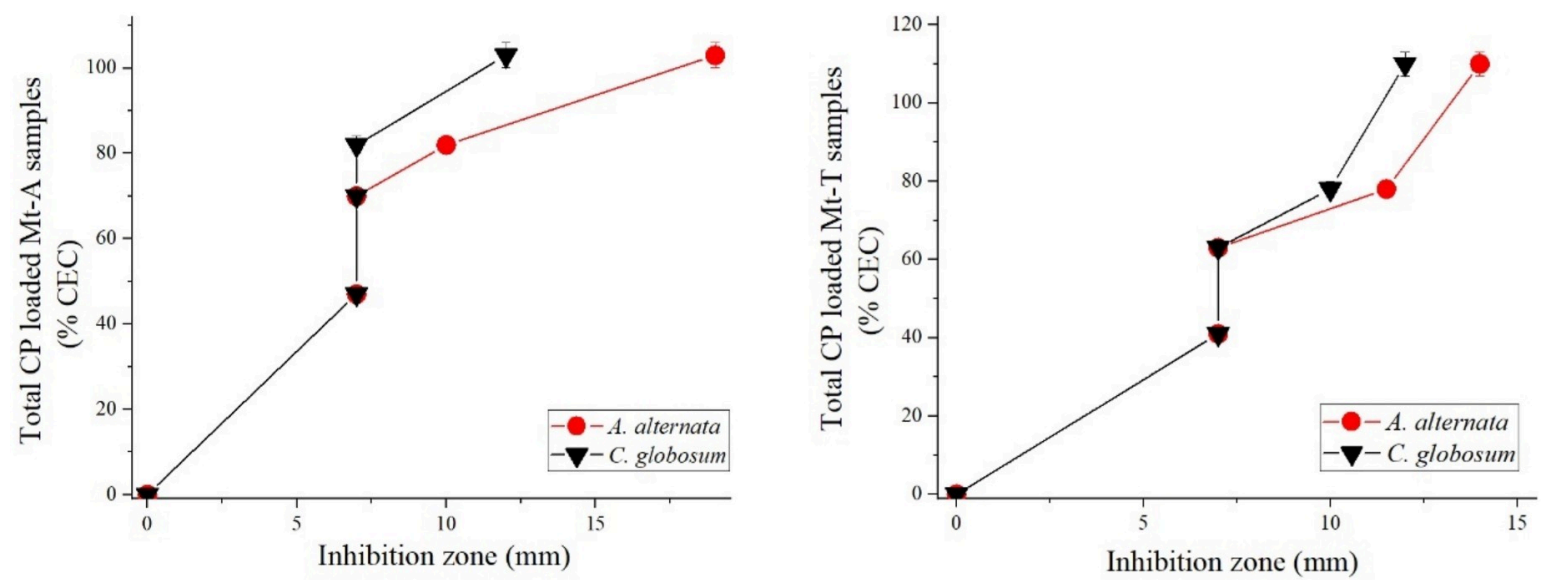

Fig. 6. Diameters of inhibition zone ( $\mathrm{mm}$ ) against both fungal strains vs total CP loaded in the indicated Mt sample. 
diameter of the CP-loaded samples, Fig. 7 shows the \% CP loaded disaggregated according to $\mathrm{A}, \mathrm{B}$, and $\mathrm{C}$ processes vs the inhibition zone of both fungi. In this sense, it is necessary to take into account that higher inhibition zone diameters are related to a higher ability to diffuse in the culture medium. For the Mt-A sample for both fungi, the $\mathrm{C}$ process (CP into the interlayer space) remained relatively constant after reaching an inhibition zone greater than 7 , while the $\mathrm{CP}$ amount located at the external surface by A and B processes increases with the inhibition zone. Different behavior is observed for the Mt-T sample where the inhibition zone increases, for both fungi, increases with the $\mathrm{CP}$ bonded to Mt-T via the three identified processes.

Particularly, for both samples, the increase of the inhibition zone by the amount of $\mathrm{CP}$ related to the B process is more significant than that observed for the other processes, which would indicate a direct relation of the inhibition zone diameter with the CP loaded preferentially to the external surface of both Mt samples.

The Pearson Correlation Coefficient (95\% confidence level), between inhibition diameters and \% of CP loaded related to each process, taking into account data obtained for both Mt samples are presented in Table 6. The coefficients resulted significant only for CP loaded at the external surface, related to A and $\mathrm{B}$ processes, indicating that $\mathrm{CP}$ at the external surfaces is relevant for a controlled release of the CP from the organoclays.

\section{Conclusions}

Two bentonite samples from Turkey and Argentine were loaded with different CP concentrations, characterized, and tested against A. alternata and C. globosum.
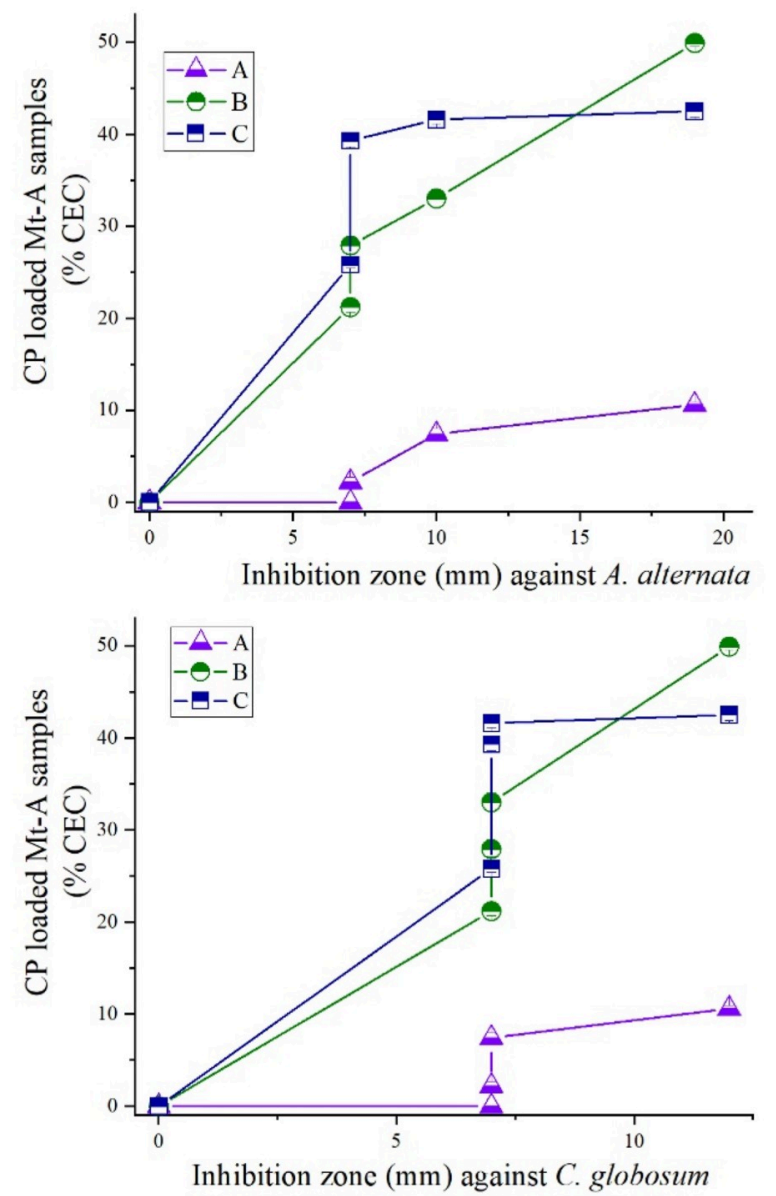

Table 6

Pearson Correlation Coefficient (95\% confidence level) between inhibition diameters obtained and \% of CP loaded, related to each process. Ns means no significant correlation.

\begin{tabular}{lll}
\hline Process & A. alternata & C. globosum \\
\hline A & 0.87 & 0.84 \\
B & 0.84 & 0.91 \\
A + B & 0.87 & 0.92 \\
C & ns & ns \\
\hline
\end{tabular}

DTGA peak analysis allowed observing and quantifying the occurrence of three simultaneous $\mathrm{CP}$ sorption process on the surface of montmorillonites: cation exchange between $\mathrm{CP}$ and the Mt interlayer ions (C), electrostatic interactions between $\mathrm{CP}$ and the negative external sorption sites of Mt (B) and van der Waals interactions between the own surfactant molecules (A) with the already adsorbed CP molecules by B process.

Organo-montmorillonites showed antifungal activity against A. alternata and C. globosum. DTGA quantification analyses and diffusion test results allow concluding that, employing the Pearson correlation coefficient, $\mathrm{CP}$ occurring at the external Mt surface (processes A and B) are crucial for antifungal purposes. Considering that $\mathrm{CP}$ was supported onto the Mt sites maintaining its antifungal activity, these materials are proposed for antifungal applications.

The proposed DTGA peak analysis methodology could provide relevant information about the expected antifungal properties of organoclay samples.
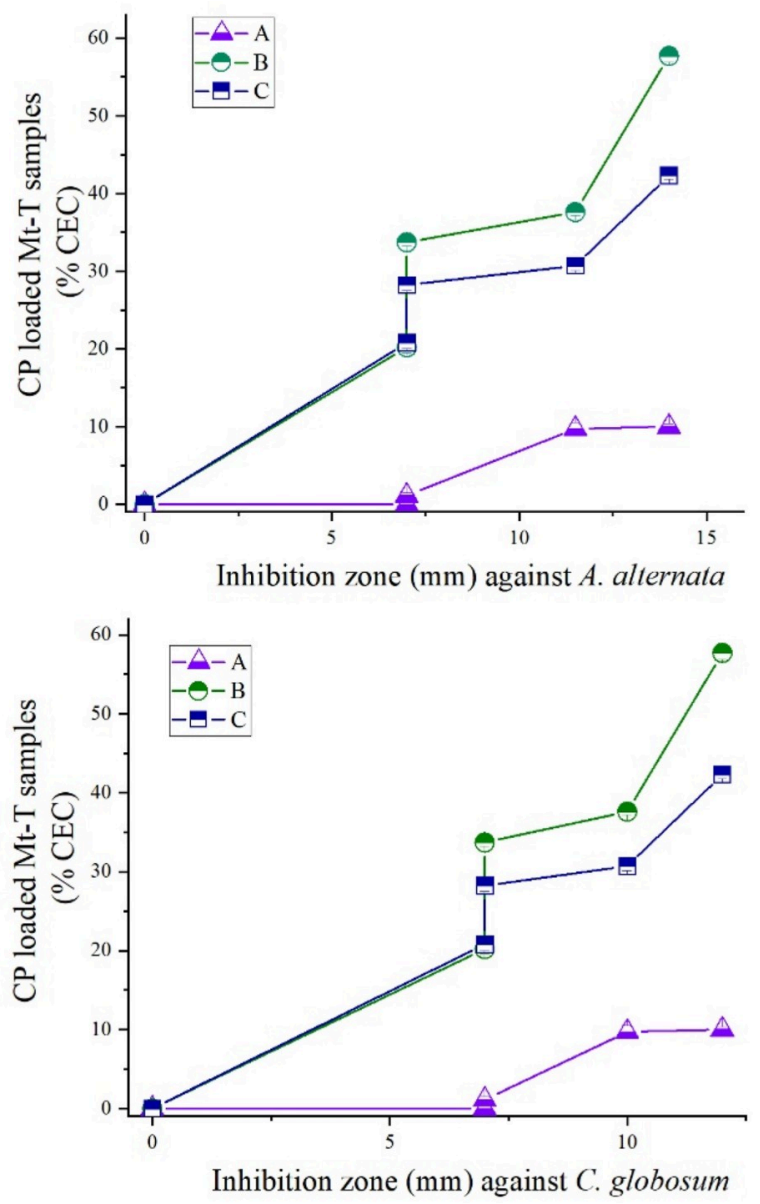

Fig. 7. Diameters of inhibition zone (mm) against each fungal strain for CP loaded by process A, B, or C. 


\section{Declaration of competing interest}

The authors declare that they have no known competing financial interests or personal relationships that could have appeared to influence the work reported in this paper.

\section{CRediT authorship contribution statement}

Florencia Yarza: Investigation, Data curation, Writing - original draft, Writing - review \& editing, Conceptualization, Methodology, Visualization, Formal analysis, Investigation, Project administration. Cesar Fernández Morantes: Methodology, Software, Validation, Investigation, Formal analysis, Writing - review \& editing. María L. Montes: Methodology, Writing - review \& editing, Visualization, Formal analysis, Funding acquisition. Natalia Bellotti: Methodology, Visualization, Investigation, Writing - original draft. Joaquin Salduondo: Methodology, Investigation. Saadet Yapar: Investigation, Writing - review \& editing, Visualization. Fernanda Cravero: Supervision. Rosa M. Torres Sánchez: Supervision, Investigation, Resources, Conceptualization, Writing - review \& editing, Funding acquisition, Project administration.

\section{Acknowledgments}

Financial support of the Argentine Ministry of Science and technology, ANPCyT- PICT-2018-01536 and ANPCyT-PICT 585/2014 are gratefully acknowledged. N. Bellotti, F. Cravero, and M.L. Montes are members of the National Council of Scientific and Technological Research (CONICET). F. Yarza, C. Fernández Morantes, and J. Salduondo acknowledge CONICET fellowships. The authors thank Prof. M. S. Conconi from CETMIC-UNLP for the Rietveld analysis and English editing and review services supplied by A. Bursztyn.

\section{Appendix A. Supplementary data}

Supplementary data to this article can be found online at https://doi. org/10.1016/j.matchemphys.2020.123390.

\section{References}

[1] H.A. Burge, The fungi, in: Indoor Air Quality Handbook, Engineering Handbks, Mcgraw-hill, 2000, p. 45, 1-45.33.

[2] O.C.G. Adan, R.A. Samson (Eds.), Fundamentals of Mold Growth in Indoor Environments and Strategies for Healthy Living, Wageningen Academic Publishers, The Netherlands, 2011, https://doi.org/10.3920/978-90-8686-722-6.

[3] K. Fog Nielsen, Mycotoxin production by indoor molds, Fungal Genet. Biol. 39 (2003) 103-117, https://doi.org/10.1016/S1087-1845(03)00026-4.

[4] S. Buffet-Bataillon, P. Tattevin, M. Bonnaure-Mallet, A. Jolivet-Gougeon, Emergence of resistance to antibacterial agents: the role of quaternary ammonium compounds - a critical review, Int. J. Antimicrob. Agents 39 (2012) 381-389.

[5] Y. Ke, L. Jiao, Z. Song, K. Xiao, T. Lai, J. Lu, C. Hu, Effects of cetylpyridiniummontmorillonite, as alternative to antibiotic, on the growth performance, intestinal microflora and mucosal architecture of weaned pigs, Anim. Feed Sci. Technol. 198 (2014) 257-262.

[6] D. Wieczorek, K. Michocka, D. Kwasniewska, K. Kluczynska, Antibacterial Activity of Selected Surfactants, 2014.

[7] L. Nordstierna, A.A. Abdalla, M. Masuda, G. Skarnemark, M. Nydén, Molecular release from painted surfaces: free and encapsulated biocides, Prog. Org. Coating 69 (2010) 45-48, https://doi.org/10.1016/j.porgcoat.2010.05.002.

[8] D. Druvari, N. Koromilas, V. Bekiari, G. Bokias, J. Kallitsis, Polymeric antimicrobial coatings based on quaternary ammonium compounds, Coatings 8 (2017) 8, https://doi.org/10.3390/coatings8010008.

[9] L.E. Mardones, M.S. Legnoverde, J.D. Monzón, N. Bellotti, E.I. Basaldella, Increasing the effectiveness of a liquid biocide component used in antifungal waterborne paints by its encapsulation in mesoporous silicas, Prog. Org. Coating 134 (2019) 145-152, https://doi.org/10.1016/j.porgcoat.2019.04.058.

[10] J. Karasa, V. Nikolajeva, J. Kostjukovs, Organoclays-a promising antibacterial and antifungal additive to building materials, in: Presented at the the 10th Baltic States Restorers' Triennial Meeting Seeking Balance: Preservation Use Conservation in Riga, 2014.

[11] G. Cowan, Statistical Data Analysis, Oxford university press, 1998.

[12] G. Özdemir, S. Yapar, M.H. Limoncu, Preparation of cetylpyridinium montmorillonite for antibacterial applications, Appl. Clay Sci. 72 (2013) 201-205, https://doi.org/10.1016/j.clay.2013.01.010
[13] P. Herrera, R.C. Burghardt, T.D. Phillips, Adsorption of Salmonella enteritidis by cetylpyridinium-exchanged montmorillonite clays, Vet. Microbiol. 74 (2000) 259-272, https://doi.org/10.1016/S0378-1135(00)00157-7.

[14] G. Özdemir, S. Yapar, Preparation and characterization of copper and zinc adsorbed cetylpyridinium and N-lauroylsarcosinate intercalated montmorillonites and their antibacterial activity, Colloids Surf. B Biointerfaces 188 (2020) 110791, https://doi.org/10.1016/j.colsurfb.2020.110791.

[15] S. Yapar, M. Ateş, G. Özdemir, Preparation and characterization of sodium lauroyl sarcosinate adsorbed on cetylpyridinium-montmorillonite as a possible antibacterial agent, Appl. Clay Sci. 150 (2017) 16-22, https://doi.org/10.1016/j. clay.2017.08.025.

[16] M. Pospíšil, P. Čapková, D. Měřínská, Z. Maláč, J. Šimoník, Structure analysis of montmorillonite intercalated with cetylpyridinium and cetyltrimethylammonium: molecular simulations and XRD analysis, J. Colloid Interface Sci. 236 (2001) 127-131, https://doi.org/10.1006/jcis.2000.7360.

[17] A.A. Atia, F.M. Farag, A.E.-F.M. Youssef, Studies on the adsorption of dodecylbenzenesulfonate and cetylpyridinium bromide at liquid/air and bentonite/liquid interfaces, Colloids Surf. Physicochem. Eng. Asp. 278 (2006) 74-80, https://doi.org/10.1016/j.colsurfa.2005.11.091.

[18] P. Praus, M. Turicová, S. Študentová, M. Ritz, Study of cetyltrimethylammonium and cetylpyridinium adsorption on montmorillonite, J. Colloid Interface Sci. 304 (2006) 29-36, https://doi.org/10.1016/j.jcis.2006.08.038.

[19] Y. Xi, R.L. Frost, H. He, Modification of the surfaces of Wyoming montmorillonite by the cationic surfactants alkyl trimethyl, dialkyl dimethyl, and trialkyl methyl ammonium bromides, J. Colloid Interface Sci. 305 (2007) 150-158, https://doi. org $/ 10.1016 /$ j.jcis.2006.09.033.

[20] G. Bulut, M. Chimeddorj, F. Esenli, M. Celik, Production of desiccants from Turkish bentonites, Appl. Clay Sci. 46 (2009) 141-147.

[21] H. Yalçin, G. Gümüşer, Mineralogical and geochemical characteristics of late Cretaceous bentonite deposits of the Kelkit Valley Region, northern Turkey, Clay Miner. 35 (2016) 807-825, https://doi.org/10.1180/000985500547250.

[22] F. Esenli, B.E. Şans, XRD studies of opals ( $4 \AA$ peak) in bentonites from Turkey: implications for the origin of bentonites, Neues Jahrb. Für Miner. Abh. J. Mineral. Geochem. 191 (2013) 45-53.

[23] M. Uliana, D. Dellapé, Estratigrafía y evolución paleoambiental de la sucesión maastrichtiana-eoterciaria del engolfamiento neuquino (Patagonia Septentrional), in: Presented at the Congreso Geológico Argentino, 1981, pp. 673-711.

[24] R. Andreis, A. Iñiguez Rodríguez, J. Lluch, D. Sabio, Estudio sedimentológico de las formaciones del Cretácico superior del área del Lago Pellegrini (Provincia de Río Negro, República Argentina), Rev. Asoc. Geol. Argent. 29 (1974) 85-104.

[25] J.M. Valles, Posición estratigrafica y distribución de los horizontes de bentonita en Rio Negro, Neuquén y La Pampa, in: Actas X Congreso Geológico Argentino. Presented at the X Congreso Geológico Argentino, Tucumán, 1986, pp. 33-37.

[26] M.S. Sheikh, A.J. Khanam, R.H. Matto, Kabir-ud-Din, Comparative study of the micellar and antimicrobial activity of gemini-conventional surfactants in pure and mixed micelles, J. Surfactants Deterg. 16 (2013) 503-508, https://doi.org/ 10.1007/s11743-012-1430-4.

[27] H.M. Rietveld, A profile refinement method for nuclear and magnetic structures, J. Appl. Crystallogr. 2 (1969) 65-71, https://doi.org/10.1107/ S0021889869006558.

[28] L. Ammann, F. Bergaya, G. Lagaly, Determination of the cation exchange capacity of clays with copper complexes revisited, Clay Miner. 40 (2005) 441-453, https:// doi.org/10.1180/0009855054040182.

[29] Y.G.G. Ortega, S.A. Becerra, E.R. Ramírez, Determinación y Análisis de Fórmulas Estructurales de Esmectitas del Estado de Guanajuato, vol. 12, 2002, p. 7.

[30] J. Magnusson, J. Schnürer, Lactobacillus coryniformis subsp. coryniformis strain $\mathrm{Si} 3$ produces a broad-spectrum proteinaceous antifungal compound, Appl. Environ. Microbiol. 67 (2001) 1-5.

[31] N. Bellotti, L. Salvatore, C. Deyá, M. Del Panno, B. Del Amo, R. Romagnoli, The application of bioactive compounds from the food industry to control mold growth in indoor waterborne coatings, Colloids Surf. B Biointerfaces 104 (2013) 140-144.

[32] C. Deyá, N. Bellotti, Biosynthesized silver nanoparticles to control fungal infections in indoor environments, Adv. Nat. Sci. Nanosci. Nanotechnol. 8 (2017).

[33] S. Kaufhold, R. Dohrmann, K. Ufer, F.M. Meyer, Comparison of methods for the quantification of montmorillonite in bentonites, Appl. Clay Sci. 22 (2002) 145-151, https://doi.org/10.1016/S0169-1317(02)00131-X.

[34] B.B. Velde, A. Meunier, The Origin of Clay Minerals in Soils and Weathered Rocks, Springer Science \& Business Media, 2008.

[35] E. Murad, J. Cashion, Mössbauer Spectroscopy of Environmental Materials and Their Industrial Utilization, Springer Science \& Business Media, 2011.

[36] F. Barraqué, M.L. Montes, M.A. Fernández, R.C. Mercader, R.J. Candal, R.M T. Sánchez, Synthesis and characterization of magnetic-montmorillonite and magnetic-organo-montmorillonite: surface sites involved on cobalt sorption, J. Magn. Magn Mater. 466 (2018) 376-384.

[37] E. Ferrage, Investigation of smectite hydration properties by modeling experimental X-ray diffraction patterns: Part I. Montmorillonite hydration properties, Am. Mineral. 90 (2005) 1358-1374, https://doi.org/10.2138/ am.2005.1776.

[38] M. Gamba, F.M. Flores, J. Madejová, R.M.T. Sánchez, Comparison of imazalil removal onto montmorillonite and nanomontmorillonite and adsorption surface sites involved: an approach for agricultural wastewater treatment, Ind. Eng. Chem. Res. 54 (2015) 1529-1538, https://doi.org/10.1021/ie5035804.

[39] M. Orta, M. del, F.M. Flores, C.F. Morantes, G. Curutchet, R.M. Torres Sánchez, Interrelations of structure, electric surface charge, and hydrophobicity of organomica and -montmorillonite, tailored with quaternary or primary amine cations. 
Preliminary study of pyrimethanil adsorption, Mater. Chem. Phys. 223 (2019) 325-335, https://doi.org/10.1016/j.matchemphys.2018.10.059.

[40] H. He, Z. Ding, J. Zhu, P. Yuan, Y. Xi, D. Yang, R.L. Frost, Thermal characterization of surfactant-modified montmorillonites, Clay Clay Miner. 53 (2005) 287-293, https://doi.org/10.1346/CCMN.2005.0530308.

[41] F. Wolters, K. Emmerich, Thermal reactions of smectites-relation of dehydroxylation temperature to octahedral structure, Thermochim. Acta 462 (2007) 80-88, https://doi.org/10.1016/j.tca.2007.06.002.

[42] Q. Zhou, R.L. Frost, H. He, Y. Xi, Changes in the surfaces of adsorbed paranitrophenol on HDTMA organoclay - the XRD and TG study, J. Colloid Interface Sci. 307 (2007) 50-55.

[43] S. Yariv, Differential thermal analysis (DTA) in the study of thermal reactions of organo-clay complexes, in: R. Ikan (Ed.), Natural and Laboratory-Simulated Thermal Geochemical Processes, Springer Netherlands, Dordrecht, 2003, pp. 253-296, https://doi.org/10.1007/978-94-017-0111-2 8.

[44] S. Xu, S.A. Boyd, Cationic surfactant adsorption by swelling and nonswelling laye silicates, Langmuir 11 (1995) 2508-2514, https://doi.org/10.1021/la00007a033.

[45] C.B. Hedley, G. Yuan, B.K.G. Theng, Thermal analysis of montmorillonites modified with quaternary phosphonium and ammonium surfactants, Appl. Clay Sci. 35 (2007) 180-188, https://doi.org/10.1016/j.clay.2006.09.005.

[46] A.M. Fernández Solarte, J. Villarroel-Rocha, C.F. Morantes, M.L. Montes, K. Sapag, G. Curutchet, R.M.T. Sánchez, Insight into surface and structural changes of montmorillonite and organomontmorillonites loaded with Ag, Compt. Rendus Chem. 22 (2019) 142-153.

[47] B. Schampera, D. Tunega, R. Šolc, S.K. Woche, R. Mikutta, R. Wirth, S. Dultz, G. Guggenberger, External surface structure of organoclays analyzed by transmission electron microscopy and X-ray photoelectron spectroscopy in combination with molecular dynamics simulations, J. Colloid Interface Sci. 478 (2016) 188-200, https://doi.org/10.1016/j.jcis.2016.06.008.

[48] F. Thomas, L.J. Michot, D. Vantelon, E. Montarges, B. Prelot, M. Cruchaudet, J. F. Delon, Layer charge and electrophoretic mobility of smectites, Colloids Surf. Physicochem. Eng. Asp. 159 (1999) 351-358.

[49] S.E. Miller, P. Low, Characterization of the electrical double layer of montmorillonite, Langmuir 6 (1990) 572-578.

[50] M. Ochs, B. Lothenbach, H. Wanner, H. Sato, M. Yui, An integrated sorption-diffusion model for the calculation of consistent distribution and diffusion coefficients in compacted bentonite, J. Contam. Hydrol. 47 (2001) 283-296, https://doi.org/10.1016/S0169-7722(00)00157-1. International Conference on the Chemistry and Migration Behaviour.

[51] E.M. Pecini, M.J. Avena, Measuring the isoelectric point of the edges of clay mineral particles: the case of montmorillonite, Langmuir 29 (2013) 14926-14934.

[52] A.E. Bianchi, M. Fernández, M. Pantanetti, R. Viña, I. Torriani, R.T. Sánchez, G. Punte, ODTMA+ and HDTMA+ organo-montmorillonites characterization: new insight by WAXS, SAXS and surface charge, Appl. Clay Sci. 83 (2013) 280-285.

[53] J.J. Merianos, Quaternary ammonium antimicrobial compounds, Disinfect. Steriliz. Preserv. (1991) 225-255.

[54] A.M. Fernandez Solarte, M. Blanco Massani, V. Molina, M. Bénitez Guerrero, R. M. Torres Sánchez, Correlating antimicrobial activity and structure in montmorillonite modified with hexadecyltrimethylammonium and silver, Int. J. ChemTech Res. (2018), https://doi.org/10.20902/IJCTR.2018.110627. 